\title{
Timing and executive function: Bidirectional interference between concurrent temporal production and randomization tasks
}

\author{
SCOTT W. BROWN \\ University of Southern Maine, Portland, Maine
}

\begin{abstract}
A review of interference effects in concurrent temporal/nontemporal dual-task studies suggests that prospective timing may be related to executive cognitive functions. Executive processes play a supervisory role in behavior by controlling attention, coordinating information, and scheduling actions. In the present research, a timing task was paired with an established executive task in a dual-task paradigm. The timing task required subjects to generate a series of 5-sec temporal productions, and the executive task was random number generation. These tasks were performed both separately and concurrently. Comparisons of single-task and dual-task conditions showed that (1) the randomization task interfered with timing by making temporal productions more variable and longer and (2) concurrent timing disrupted randomization performance by making responses less random. This pattern of bidirectional interference supports the idea that timing relies on the same attentional resources used by other executive-level tasks.
\end{abstract}

This study concerned the nature of the attentional resources involved in time perception. The focus was on situations in which subjects must attend to the passage of time and perform a concurrent nontemporal distractor task. Cognitive psychologists have used the dual-task situation extensively to explore competing task demands, the specialization of resources, and the dynamics of attentional deployment (e.g., Hirst \& Kalmar, 1987; Navon \& Gopher, 1980; Wickens, 1991, 1992). Interference patterns between concurrent temporal and nontemporal tasks can reveal a great deal about cognitive processes in timing.

\section{Interference Effect}

Time judgment performance is very sensitive to nontemporal task demands. In a review of temporal/nontemporal dual-task experiments, Brown (1997) found that the vast majority of studies showed an interference effect in which nontemporal tasks disrupted timing performance. The disruption is manifested as an increase in error in timing, with time judgments being shorter, more variable, or more inaccurate, relative to timing-only control conditions. Numerous researchers have characterized the interference effect in terms of a competition for attentional resources (e.g., Brown, 1985; Brown \& Bennett, 2002;

Special thanks are extended to C. Tigg Frieh, who collected the data and assisted in the analysis. An earlier version of this paper was presented at the New England Sequencing and Timing (NEST) 10th Annual Meeting, Yale University, New Haven, CT, March 2000. Correspondence should be addressed to S. W. Brown, Department of Psychology, University of Southern Maine, Portland, ME 04104-9300 (e-mail: swbrown@) usm.maine.edu).

Note-This article was accepted by the previous editorial team, when Colin M. MacLeod was Editor.
Hicks, Miller, Gaes, \& Bierman, 1977; Thomas \& Weaver, 1975; Zakay, 1989). According to an attentional allocation model, nontemporal demands divert processing capacity away from timing. The temporal task receives a suboptimal supply of resources, leading to a disruption in timing performance.

A key assumption of the attentional allocation model is that the concurrent temporal and nontemporal tasks both draw from the same resource pool. If two tasks depend on a common set of resources, then one may expect to observe a pattern of bidirectional interference. That is, each task interferes with performance of the other, producing a joint "concurrence cost" (Navon \& Gopher, 1979). However, the dual-task timing literature is inconsistent on this issue. Some studies show mutual interference, and some show interference patterns that are asymmetric, in which the nontemporal task interferes with timing performance but timing does not interfere with nontemporal performance.

\section{Bidirectional Interference Studies}

Most studies on the interference effect treat the nontemporal task strictly as a distractor task designed to divert subjects' attention away from timekeeping. Performance on the nontemporal task typically is not measured, and a control condition involving the nontemporal task alone is rarely employed. However, these features are critical for assessing the issue of bidirectional interference. A survey of the literature uncovered 33 interference experiments that overcame these deficiencies. All these studies meet the following criteria: (1) Performance indices for both the temporal and the nontemporal tasks were recorded, and (2) the experimental design included conditions in which the temporal and nontemporal tasks were performed separately as well as concurrently. 
Sixteen of the studies showed bidirectional interference, and 15 showed interference with the timing task only. Two studies (Kantowitz \& Knight, 1976, Experiment 1; Thomas \& Cantor, 1975) failed to exhibit the interference effect in timing, although both found that timing interfered with nontemporal task performance (mental arithmetic and size judgments, respectively). Turning first to those experiments demonstrating bidirectional interference, five involved arithmetical processing as the nontemporal task (Brown, 1997, Experiment 3; Kantowitz \& Knight, 1974; Kantowitz \& Knight, 1976, Experiment 2; Klapp, Porter-Graham, \& Hoifjeld, 1991, Experiment 1; Wierwille, Rahimi, \& Casali, 1985). Four studies involved attentional or working memory tasks (Brown, 1985, Experiment 2; Brown \& Frieh, 2000; Franssen \& Vandierendonck, 2002, Experiment 1; Shinohara, 1999), and two employed a reading task (Brown \& Stubbs, 1992; Hiscock, Cheesman, Inch, Chipuer, \& Graff, 1989). One experiment involved choice reaction time (Burle \& Casini, 2001). Several studies employed psychophysical judgments of stimuli (e.g., light intensity or tone intensity judgments) as the nontemporal task, and these studies produced mixed results. Four such studies (Casini \& Macar, 1997, Experiment 1; Casini, Macar, \& Grondin, 1992, Experiment 2; Coull, Vidal, Nazarian, \& Macar, 2004; Macar, Grondin, $\&$ Casini, 1994, Experiment 2) reported bidirectional interference between the concurrent timing and perceptual judgment tasks. However, three studies (Casini \& Ivry, 1999; Grondin \& Macar, 1992; Macar et al., 1994, Experiment 3 ) found that concurrent timing did not interfere with perceptual judgments.

The remaining studies reported interference with the timing task only. The single largest group of experiments in this category is a set of human factors studies involving piloting performance in flight simulators (Bortolussi, Kantowitz, \& Hart, 1986; Casali \& Wierwille, 1983, 1984; Wierwille \& Connor, 1983; Zakay \& Shub, 1998, Experiment 2). All these studies reported that the concurrent flight task interfered with timing performance but that timing did not affect flight performance. However, changes in attentional allocation complicate the interpretation of the findings. Casali and Wierwille (1983) noted that many of their subjects ignored timing when flight demands increased, and Casali and Wierwille (1984) explicitly instructed subjects not to allow timing to interfere with the primary task of flying. The remaining experiments in this category represent an assortment of nontemporal tasks, including anagrams (Bathurst \& Kee, 1994; Kee, Morris, Bathurst, \& Hellige, 1986), target search (Brown, 1997, Experiment 2; Thomas \& Cantor, 1978), card sorting (Hicks, Miller, \& Kinsbourne, 1976), tracking (Brown, 1997, Experiment 1), and word categorization (Macar et al., 1994, Experiment 1). In each case, interference effects were unidirectional, with increased error restricted to timing performance only.

How can one summarize these studies? Most of the experiments demonstrating bidirectional interference tend to involve higher level cognitive processes, such as mental arithmetic, reading, and attentional tasks. Many of the experiments in which interference was limited to timing involve perceptual or perceptual-motor tasks, such as stimulus intensity judgments, pattern detection, tracking, and flight simulator performance. Several critical factors complicate the interpretation of the studies beyond these basic findings. One problem is that the experiments vary considerably in terms of procedure, time judgment method, and interval duration. In some studies, the relative emphasis given to the tasks is unclear. Unequal amounts of attention directed to temporal and nontemporal processing can produce dramatic differences in interference patterns (Casini et al., 1992; Grondin \& Macar, 1992; Macar et al., 1994; Zakay, 1998). Another issue is that different measures of task performance vary significantly in their ability to detect changes in resource demands (O'Donnell \& Eggemeier, 1986; Wickens, 1992), with the result that some indices may fail to detect actual performance decrements. Probably the main drawback in this research is that most experiments were not designed with any underlying theoretical importance assigned to the nontemporal tasks, other than the notion of attention being divided between temporal and nontemporal processing.

The nature of the distractor tasks is an important issue within the context of a multiple-resource model of attention (e.g., Kantowitz \& Knight, 1976; Navon \& Gopher, 1979; Wickens, 1980, 1984, 1986, 1991). In this view, the cognitive system includes separate pools of specialized attentional resources. The model predicts that tasks relying on the same specialized resources will produce greater interference than will tasks that rely on different resources. Asymmetry in dual-task interference is attributed to an unequal or partial overlap in the resources that support the two tasks (e.g., Tsang, Shaner, \& Vidulich, 1995). These concepts may be applied to the bidirectional interference timing studies. One recent formulation proposes that temporal information processing is handled by executivelevel resources that are separate from resources dedicated to other specialized task demands, such as motor control, visual perception, and phonological processing (Brown, 1997; Brown \& Frieh, 2000).

\section{Executive Processes and Timing}

Executive processes serve to organize and control thought and behavior (Stuss \& Alexander, 2000). One prominent model of executive function is the working memory (WM) model (Baddeley, 1992, 1994; Baddeley \& Hitch, 1974), a multicomponent view of short-term memory emphasizing multiple processing resources. The main component, the central executive, is an attentional controller mechanism that integrates multiple inputs, coordinates dual-task performance, and is responsible for higher level cognitive processes, such as reasoning, comprehension, and decision making (Baddeley, 1990; Baddeley \& Della Sala, 1996; Gilhooly, Logie, Wetherick, \& Wynn, 1993; Logie, Zucco, \& Baddeley, 1990). Research on the WM model relies extensively on dual-task methodology. Executive tasks, such as reading comprehension, mathematical problem solving, and syllogistic reasoning, are commonly employed as "suppressor tasks" in dual- 
task experiments to determine whether a particular target task relies on central executive resources. Impairment of the target task by the concurrent executive task implies that the target task also involves executive processes.

How do executive attentional resources relate to judgments of time? The conscious, intentional nature of prospective timekeeping, requiring continuous monitoring and updating of the passage of time, logically aligns time perception with executive functioning. Furthermore, the executive processes of coordination and scheduling are essentially temporal in nature. The interference effect in timing may be explained by reference to the executive functions of integration, organization, and scheduling (Brown, 1997). The dual-task situation engages these coordination functions, thereby drawing some resources away from timing. The result is the classic interference effect, with time judgments showing more error. The issue of bidirectional interference hinges on the exact nature of the nontemporal task. If the nontemporal task relies on nonexecutive resources, then interference may be restricted to the timing task only. In this case, the workload demands of the nontemporal task may be partially or completely managed by resources from a different resource pool. However, if the nontemporal task itself engages executive functions, then the task is placed in direct competition with the timing task for executive-level resources. This circumstance is likely to lead to a pattern of mutual (i.e., bidirectional) interference between the temporal and nontemporal tasks.

\section{The Present Experiment}

In the present experiment, timing was combined with a task involving random generation. Random generation requires that the subject produce responses (typically a continuous series of numbers or letters) in a random sequence (see Nickerson, 2002, for a review). Baddeley (1986, 1990, 1993, 1994) has argued that randomization requires a heavy involvement of central executive resources. Indeed, numerous dual-task studies have produced interference patterns indicating that randomization competes for the same attentional resources used by other executive tasks (e.g., Baddeley, Emslie, Kolodny, \& Duncan, 1998; Lemaire, Abdi, \& Fayol, 1996; Robbins et al., 1996; Stuyven \& Van der Goten, 1995; Teasdale et al., 1995; Towse \& Valentine, 1997). In the present case, this same methodology was used to study time perception. The hypothesized connection between timing and executive function leads to the prediction that concurrent timing and randomization tasks will produce bidirectional interference relative to single-task baseline levels of performance. Mutual interference would imply that the two tasks draw from the same pool of processing resources.

\section{METHOD}

\section{Subjects}

Thirty-five psychology students ( 7 males, 28 females) at the University of Southern Maine volunteered for the experiment in return for extra course credit. The average age of the students was 26.1 years (range $=18-49$ years).

\section{Apparatus and Stimuli}

An Apple II-GS computer equipped with a mouse device and a Timemaster II H.O. clock card (Applied Engineering) set at an interrupt rate of $1024 \mathrm{~Hz}$ was programmed to record time judgment responses. In addition, an electronic digital metronome (Seiko Model DM-10) was used to demonstrate a target rate for random number generation (see below).

\section{Design and Procedure}

The subjects were tested individually in two sessions separated by 2 weeks. Each session lasted approximately $35 \mathrm{~min}$. Watches were removed at the start of each session. Session 1 involved single tasks, in which the timing task and two different versions of a random number generation (RNG) task were performed separately. Session 2 involved dual tasks, in which timing was performed concurrently with each of the two RNG tasks. In all cases, the tasks were performed for four 2-min trials. The order in which the tasks were performed within each session was counterbalanced across subjects.

The timing task involved serial temporal production. The subjects held the computer-linked mouse device in hand and were asked to press the mouse button every $5 \mathrm{sec}$. This procedure has been used in previous research on time and attention (e.g., Brown, 1997, 1998; Brown \& Bennett, 2002) and provides an online measure of timing performance over a continuous period. The subjects were not given any practice or feedback for this task, but they were simply encouraged to press the button at a steady rate and to be as accurate as possible in their timing responses. As in most time perception studies, the primary interest is on relative differences in timing performance between different experimental conditions, rather than how well performance conforms to an objective standard (see, e.g., Ornstein, 1969).

For the RNG task, the subjects were asked to verbalize a continuous series of random digits. Prior to each trial, the subjects were provided with a brief practice interval, during which the experimenter played an electronic metronome set at 70 beats per minute (approximately 1 beat every $0.86 \mathrm{sec}$ ). The subjects practiced generating random digits in pace with the metronome. The metronome was turned off during the actual data collection trials. There were two versions of the RNG task. In the easy version, the subjects had to generate digits in the range of 1-10 inclusive. In the difficult version of the task, the subjects were required to generate digits in the range of 34-43 inclusive. In order to reduce errors, a card with the appropriate digit range printed on it was placed before the subject during each trial. The randomization responses were transcribed by the experimenter as they were given. In the dual-task conditions, the subjects performed the timing and RNG tasks concurrently. They were instructed to regard the tasks as being equally important and to devote the same amount of attention to each one.

\section{RESULTS AND DISCUSSION}

\section{Timing Performance}

The entire time judgment data set consists of 9,720 temporal productions. These responses were converted into two standard measures for analysis. The measures are the coefficient of variation $(\mathrm{CV})$ and the mean interresponse interval (IRI).

Coefficient of variation. The $\mathrm{CV}$ is a relative measure of timing variability, formed by dividing the standard deviation of temporal productions by the mean temporal production. $\mathrm{CV}$ scores are very sensitive at detecting various experimental manipulations designed to influence timing performance (e.g., Brown, 1997, 1998; Hiscock et al., 1989; Kee et al., 1986). Because a preliminary analysis indicated that the trials variable did not exert any 
significant effects, the scores were collapsed across the four trials and were submitted to a one-way repeated measures ANOVA. This analysis compared the timing-only single task, timing + easy RNG dual-task, and timing + difficult RNG dual-task attention conditions. The effect for task was significant $\left[F(2,68)=59.07, M S_{\mathrm{e}}=0.01\right.$, $\left.p<.001, \eta_{\mathrm{p}}^{2}=.64\right]$. As shown in Table 1, the addition of the randomization task disrupted timing by making responses more variable. Orthogonal comparisons were used to test for differences between the task conditions. Contrast 1 , comparing the single-task (timing-only) condition $(M=0.10 \mathrm{sec})$ versus the combination of the two dual-task conditions (combined $M=0.38 \mathrm{sec}$ ), was significant $\left[F(1,34)=114.99, M S_{\mathrm{e}}=0.01, p<.001, \eta_{\mathrm{p}}^{2}=\right.$ .77]. This result corresponds to the classic interference effect in timing: The addition of a concurrent distractor task disrupted timing performance by making responses more variable. Contrast 2 , comparing the two dual-task conditions, was not significant $(F<1)$. The easy and difficult versions of the RNG task disrupted concurrent timing to an equal degree.

Interresponse interval. The IRI corresponds to the average temporal production. The IRI is a directional measure of error, indicating whether there is any consistent trend toward overestimation or underestimation. Mean IRI scores, calculated for each subject in each task condition, were submitted to a one-way repeated measures ANOVA. ${ }^{1}$ The significant task effect $\left[F(2,68)=22.24, M S_{\mathrm{e}}=1.16, p<\right.$ $\left..001, \eta_{\mathrm{p}}^{2}=.40\right]$ was probed with orthogonal comparisons (see Table 1). Contrast 1 showed that temporal productions lengthened from the timing-only condition $(M=4.4 \mathrm{sec})$ to the combined dual-task conditions $(M=6.0 \mathrm{sec})[F(1,34)=$ $\left.29.52, M S_{\mathrm{e}}=1.73, p<.001, \eta_{\mathrm{p}}^{2}=.46\right]$. In time judgment methodology, longer temporal productions correspond to an underestimation of time (Fraisse, 1978, pp. 215-217; Zakay, 1993). This pattern fits in with other studies on the interference effect reporting shorter temporal judgments in response to nontemporal task demands (see Brown, 1997). As in the case of the CV, Contrast 2 indicated that the easy $(M=6.0 \mathrm{sec})$ and difficult $(M=6.1 \mathrm{sec}) \mathrm{RNG}$ tasks were equally disruptive.

\section{Randomization Performance}

The subjects produced 63,325 responses on the RNG task, of which 62,044 were valid responses and 1,281 (approximately $2 \%$ of the total) were out-of-range errors. This large data set provides a great deal of information on randomization performance under the various experimental conditions. The number of valid responses (collapsed over the four trials) contributed by each subject ranged from a minimum of 255 to a maximum of 884 . These data were entered into four separate analyses, each involving a different dependent variable. Many different measures have been created to assess randomization (see Ginsburg \& Karpiuk, 1994; Towse \& Neil, 1998), but there is no single measure that serves as a standard index. The literature suggests that random generation performance is not a unitary skill, and so different measures may reflect different aspects of performance (e.g., Brugger, 1997).
Table 1

Mean Scores and Standard Errors for Two Timing

Performance Measures in Different Attention Conditions

\begin{tabular}{|c|c|c|c|c|}
\hline \multirow[b]{2}{*}{ Attention Condition } & \multicolumn{2}{|c|}{$\begin{array}{c}\text { Coefficient of } \\
\text { Variation }\end{array}$} & \multicolumn{2}{|c|}{$\begin{array}{c}\text { Interresponse } \\
\text { Interval } \\
\end{array}$} \\
\hline & $M$ & $S E$ & $M$ & $S E$ \\
\hline Timing only & 0.10 & 0.01 & 4.4 & 0.2 \\
\hline Timing + easy RNG & 0.41 & 0.07 & 6.0 & 0.4 \\
\hline Timing + difficult RNG & 0.35 & 0.02 & 6.1 & 0.3 \\
\hline
\end{tabular}

Note-All values are expressed in seconds. RNG, random number generation.

The four measures selected for analysis were redundancy, the RNG index, coupon scores, and the repetition gap. The selection of these measures was informed by a principle components factor analysis involving a variety of randomization indices conducted by Towse and Neil (1998). The analysis extracted four factors; the measures reported here load onto three of the factors (some measures contributed to more than one factor). The factor not represented here applies only to small sequence lengths. The measures were calculated with software provided by Neil and Towse (1997; see Towse and Neil, 1998, for the computational details).

Redundancy. The redundancy $(R)$ measure is one of the most commonly used indices of randomization. This measure is derived from information theory (Attneave, 1959; Shannon \& Weaver, 1949). A sequence of items has maximum first-order information when each response alternative is selected equally often. However, if particular responses are selected too frequently (or too infrequently), then the sequence has more redundancy (i.e., less randomness). Scores can range from $0 \%$ (maximum randomness) to $100 \%$ (maximum redundancy; i.e., the same response alternative repeated over and over). Redundancy scores were computed for each subject and cast in the form of a $2 \times 2$ repeated measures ANOVA. The variables were randomization (easy vs. difficult) and task (single task vs. dual task). Both main effects were significant (see Table 2). The effect for randomization $[F(1,34)=28.69$, $\left.M S_{\mathrm{e}}=0.73, p<.001, \eta_{\mathrm{p}}^{2}=.46\right]$ indicates that the difficult RNG task $(M=2.0)$ is associated with greater redundancy (i.e., less randomness) compared with the easy RNG task $(M=1.2)$. Of greater interest is the task main effect $\left[F(1,34)=21.87, M S_{\mathrm{e}}=0.66, p<.001, \eta_{\mathrm{p}}^{2}=.39\right]$. Responses in the dual task $(M=1.9)$ were more redundant than those in the single task $(M=1.3)$. That is, the dual task prompted the subjects to produce unequal frequencies of the response alternatives. This result is in line with the prediction that concurrent timing should interfere with randomization performance. The interaction was not significant.

RNG index. The RNG index (Evans, 1978; Evans \& Graham, 1980) is another common measure of randomness. One drawback of the $R$ statistic is that it considers only the frequency of responses. For example, if one simply repeated over and over the digits $1-10$ in order, a low-redundancy score would be produced, falsely implying that the responses were random. The RNG index 
Table 2

Mean Scores and Standard Errors for Four Randomization Performance Measures in Different Attention and Randomization Conditions

\begin{tabular}{|c|c|c|c|c|}
\hline \multirow[b]{3}{*}{ Attention Condition } & \multicolumn{4}{|c|}{ Randomization Condition } \\
\hline & \multicolumn{2}{|c|}{ Easy } & \multicolumn{2}{|c|}{ Difficult } \\
\hline & $M$ & $S E$ & $M$ & $S E$ \\
\hline & \multicolumn{4}{|c|}{ Redundancy $(R)$} \\
\hline Single task & 1.0 & 0.1 & 1.6 & 0.2 \\
\hline \multirow[t]{2}{*}{ Dual task } & 1.4 & 0.2 & 2.4 & 0.3 \\
\hline & \multicolumn{4}{|c|}{ RNG Index } \\
\hline Single task & 0.49 & 0.01 & 0.46 & 0.01 \\
\hline \multirow[t]{2}{*}{ Dual task } & 0.51 & 0.01 & 0.48 & 0.01 \\
\hline & \multicolumn{4}{|c|}{ Coupon } \\
\hline Single task & 22.0 & 0.8 & 27.5 & 1.6 \\
\hline \multirow[t]{2}{*}{ Dual task } & 24.3 & 1.3 & 31.6 & 1.9 \\
\hline & \multicolumn{4}{|c|}{ Repetition Gap } \\
\hline Single task & 8.5 & 0.1 & 8.0 & 0.1 \\
\hline Dual task & 8.3 & 0.1 & 7.6 & 0.1 \\
\hline
\end{tabular}

Note-RNG, random number generation.

overcomes this problem by considering the distribution of response pairs (digrams). It measures how often any response follows any other response. The index ranges from 0 (perfect randomness) to 1 (complete predictability). RNG scores (see Table 2) were submitted to a $2 \times 2$ (randomization $\times$ task) analysis. The randomization main effect $\left[F(1,34)=48.24, M S_{\mathrm{e}}=0.001, p<.001, \eta_{\mathrm{p}}^{2}=.60\right]$ indicates that scores declined from the easy $(M=0.50)$ to the difficult $(M=0.47)$ conditions. Given the outcome of the redundancy analysis reported above, one might have predicted the opposite pattern - that the difficult condition be associated with higher RNG scores (meaning less randomness). One possibility is that the digits $1-10$ comprise a more familiar series, thus making it harder for subjects to avoid producing repetitive digrams. The primary result, however, concerns the task effect $[F(1,34)=13.31$, $\left.M S_{\mathrm{e}}=0.001, p<.001, \eta_{\mathrm{p}}^{2}=.25\right]$. As predicted, the dual task $(M=0.50)$ is associated with higher RNG scores relative to the single task $(M=0.48)$, indicating a greater departure from randomness for the dual-task condition. The timing task interfered with randomization by causing the subjects to produce a less even distribution of response pairs. The interaction was not significant.

Coupon. The coupon score (Ginsburg \& Karpiuk, 1994) represents the average number of responses produced before all the response alternatives are given. If one repeats responses, or forgets to name some responses, the coupon score becomes larger. Therefore, lower scores indicate more randomness, and higher scores are less random. In the present case, the coupon score can range from 10 to the total number of valid responses generated (a mean of 452 , averaged across all subjects, trials, and conditions). The $2 \times 2$ repeated measures ANOVA yielded significant main effects for randomization $\left[F(1,34)=21.54, M S_{\mathrm{e}}=\right.$ $\left.66.41, p<.001, \eta_{\mathrm{p}}^{2}=.39\right]$ and task $[F(1,34)=12.78$, $\left.M S_{\mathrm{e}}=27.45, p<.001, \eta_{\mathrm{p}}^{2}=.27\right]$. The difficult condition $(M=29.6)$ is less random than the easy condition
$(M=23.2)$. More importantly, the dual task $(M=27.9)$ shows less randomness than the single task $(M=24.8)$ : The subjects showed a greater tendency to repeat response alternatives under dual-task conditions. The interaction did not achieve significance.

Repetition gap. Repetition gap scores (Ginsburg \& Karpiuk, 1994; Towse \& Neil, 1998) represent the distance between repeated items. Specifically, the measure employed here is the median distance (or lag) between repeated items. The computational formula calculates scores ranging from 1 to 20, with larger values signifying greater randomness. Both main effects in the ANOVA were significant. The randomization effect $[F(1,34)=$ 42.37, $\left.M S_{\mathrm{e}}=0.23, p<.001, \eta_{\mathrm{p}}^{2}=.56\right]$ revealed that the difficult condition $(M=7.8)$ is less random than the easy condition $(M=8.4)$. Consistent with all the other measures, the task effect $\left[F(1,34)=15.35, M S_{\mathrm{e}}=0.21\right.$, $\left.p<.001, \eta_{\mathrm{p}}^{2}=.31\right]$ indicated that the dual task $(M=7.9)$ shows less randomness than the single task $(M=8.3)$. Specifically, the subjects repeated responses more frequently in the dual task than in the single task. The interaction was not significant.

The experiment produced a symmetrical pattern of dual-task interference. The concurrent randomization task interfered with timing by causing temporal productions to become more variable and longer, relative to single-task (timing-only) conditions. Interference also extended in the opposite direction, with all the measures of randomization showing the same pattern of impairment under concurrent timing conditions. These data present a clear indication of bidirectional interference.

\section{GENERAL DISCUSSION}

This research may be interpreted in terms of a competition for specialized resources. The patterns of interference support the hypothesized link between resources dedicated to timing and executive functions. The following sections summarize the findings concerning timing performance, randomization performance, and the issue of bidirectional interference.

\section{Timing Performance}

The timing data showed a strong interference effect. Temporal productions were substantially more variable under dual-task (timing + randomization) conditions compared with single-task (timing-only) conditions. The timing data also showed that temporal productions lengthened from single-task to dual-task conditions. Longer productions correspond to an underestimation of time, the direction of error frequently observed in the interference effect.

According to an attentional resource account, these effects occur because a concurrent distractor task disrupts the accumulation of temporal cues. The distractor task diverts resources away from timing, and less attention directed to time leads to greater error in time judgments. This error may come in the form of shorter or more variable time judgment responses. Shorter judgments may reflect an overall reduction in the number of accumulated 
temporal cues (e.g., Zakay, 1989). Increased variability in time judgments may be related to the incompleteness of the temporal record created under dual-task conditions. Subjects may continually shift attention between temporal and nontemporal processing in an attempt to keep up with both tasks on a time-sharing basis (Brown, 1998). Consequently, some temporal productions are associated with more attention directed to time, whereas others are associated with less attention to time. The result is a mix of relatively longer and shorter time judgments, producing increased variability. This process would be particularly influential when subjects perform continuous timing and distractor tasks that require close monitoring, as in the present case.

The easy and difficult RNG tasks affected time judgments to the same degree. The dual-task timing literature has produced mixed results concerning nontemporal task difficulty. Some studies show that the more difficult version of a nontemporal task is associated with greater time judgment error than an easier version of the task; other studies show that different versions of the nontemporal task are equally disruptive. This inconsistency may reflect the fact that timing is very sensitive to nontemporal demands and that even light processing loads can produce substantial interference in time judgment performance (Brown, 1997). In the present research, "easy" and "difficult" are labels that are more relevant for randomization than for timing.

\section{Randomization Performance}

The RNG task produced a consistent set of findings. The main results concern randomization performance under single-task versus dual-task conditions. Each of the four measures of randomness revealed that randomization was poorer under dual-task (concurrent randomization + timing) conditions. These results are particularly impressive, given that the various performance indices are designed to measure different aspects of randomness. In the WM literature, randomization is considered to be the preeminent example of a task requiring executive resources. The disruption of randomization performance by a concurrent timing task points to the involvement of executive resources in temporal processing as well.

Another interesting aspect of the data concerns the rate at which the subjects generated randomization responses. The randomization and task conditions exerted a systematic influence on the number of responses the subjects produced. With respect to the randomization conditions, the subjects generated an average of 1.09 responses/sec in the easy RNG task, compared with 0.79 response/sec in the difficult RNG task. This difference in the rate of responding might have occurred because the digits 1-10 (easy task) can be verbalized faster than the digits 34-43 (difficult task). As for the task conditions, the mean response rate for the single task $(0.89$ response/sec) is very close to the metronome target rate $(0.86 \mathrm{response} / \mathrm{sec})$. The dual task is associated with a slower rate of 0.99 response/sec. From an attentional resource perspective, the slower response rate might have been a consequence of the extra processing demands imposed by concurrent timing. Did this rate of nearly 1 response/sec provide a means for the subjects to mark time by pressing the timing button after every fifth randomization response? The data show that timing performance was not improved: Accuracy was worse for the dual task $(M$ IRI $=6.0 \mathrm{sec})$ and better for the single task $(M$ IRI $=4.4 \mathrm{sec})$. Timing responses also were far more variable under dual-task $(M \mathrm{CV}=0.38 \mathrm{sec})$ than under single-task $(M \mathrm{CV}=0.10 \mathrm{sec})$ conditions. These results suggest that response output did not serve as an effective timing cue in the dual-task conditions.

\section{Bidirectional Interference}

The results are straightforward with respect to the issue of bidirectional interference. The concurrent randomization task interfered with timing performance, and concurrent timing interfered with randomization performance. These data conform to the studies reviewed earlier showing patterns of mutual interference between temporal judgments and other executive tasks. On the basis of the dual-task logic widely employed in studies of attentional resources, the implication is that prospective timing is an executive cognitive process that relies on the same resources as or similar resources to those of other executivelevel tasks.

One issue in interpreting the interference effects involves counting processes. Chronometric counting (e.g., "1-Mississippi, 2-Mississippi," etc.) is commonly employed as a strategy for timing short intervals. The randomization tasks in the present research also involved the phonological processing of numbers, and so the possibility exists that bidirectional interference effects were due to a competition for phonological rather than executive resources. There are two points that argue against this hypothesis. First, several of the bidirectional interference studies reviewed earlier employed nonverbal distractor tasks, such as color comparison judgments (Coull et al., 2004), stimulus intensity judgments (Casini \& Macar, 1997), and color memory (Franssen \& Vandierendonck, 2002). The phonological demands of these tasks are minimal or nonexistent, yet each showed bidirectional interference with timing. Second, it is important to recognize that chronometric counting is essentially a timing task in which the subject attempts to produce a series of 1 -sec intervals. The proposal here is that timing, whether mediated by phonological processes (as in counting), visual processes (imagining a second hand moving around a clock face), or motor processes (tapping a rhythmical pattern), requires executive resources. This idea does not rule out the potential contribution of other cognitive resources or mechanisms. Indeed, it is difficult to identify "pure" executive tasks (Vandierendonck, De Vooght, \& Van der Goten, 1998). For example, although mental arithmetic is considered to be an executive task, there is also evidence for the involvement of phonological and visual processes in mathematical problem solving (De Rammelaere, Stuyven, \& Vandierendonck, 1999; Fürst \& Hitch, 2000; Heathcote, 1994; Noël, Désert, Aubrun, \& Seron, 2001; Seitz \& Schumann-Hengsteler, 2000). The cogni- 
tive workload of any given executive-level task may be shared between a number of specialized resource pools. However, it is reasonable to characterize the RNG task as being strongly dependent on supervisory and control executive functions, whereas processes such as verbal production are probably more incidental to randomization performance. This view is consistent with research demonstrating that a verbal RNG task and a nonverbal random keypressing task produce equivalent responses (Baddeley et al., 1998, Experiment 1).

The main results of this study suggest that timing uses the same executive-level processing resources used by RNG. This relation also makes good conceptual sense, given that certain basic similarities exist between the two tasks. At some fundamental level, timing and randomization both emphasize an ordering and sequencing of events - functions that are essential for the self-regulation of thought and behavior. These tasks therefore probably invoke related executive cognitive mechanisms and rely on the same resource pools.

\section{REFERENCES}

Attneave, F. (1959). Applications of information theory to psychology. New York: Holt, Rinehart \& Winston.

Baddeley, A. D. (1986). Working memory. Oxford: Oxford University Press, Clarendon Press.

Baddeley, A. D. (1990). Human memory: Theory and practice. Boston: Allyn \& Bacon.

BADDELEY, A. D. (1992). Working memory. Science, 255, 556-559.

BADDELEY, A. D. (1993). Working memory or working attention? In A. D. Baddeley \& L. Weiskrantz (Eds.), Attention: Selection, awareness, and control (pp. 152-170). New York: Oxford University Press.

BADDELEY, A. D. (1994). Working memory: The interface between memory and cognition. In D. L. Schacter \& E. Tulving (Eds.), Memory systems 1994 (pp. 351-367). Cambridge, MA: MIT Press.

Baddeley, A. D., \& Della Sala, S. (1996). Working memory and executive control. Philosophical Transactions of the Royal Society of London: Series B, 351, 1397-1404.

BaDDEley, A. D., EMSLIE, H., Kolodny, J., \& DunCan, J. (1998). Random generation and the executive control of working memory. Quarterly Journal of Experimental Psychology, 51A, 819-852.

BADDEley, A. D., \& Hitch, G. (1974). Working memory. In G. H. Bower (Ed.), The psychology of learning and motivation (Vol. 8, pp. 47-89). New York: Academic Press.

Bathurst, K., \& KeE, D. W. (1994). Finger-tapping interference as produced by concurrent verbal and nonverbal tasks: An analysis of individual differences in left-handers. Brain \& Cognition, 24, 123-136.

Bortolussi, M. R., Kantowitz, B. H., \& Hart, S. G. (1986). Measuring pilot workload in a motion base trainer: A comparison of four techniques. Applied Ergonomics, 17, 278-283.

Brown, S. W. (1985). Time perception and attention: The effects of prospective versus retrospective paradigms and task demands on perceived duration. Perception \& Psychophysics, 38, 115-124.

Brown, S. W. (1997). Attentional resources in timing: Interference effects in concurrent temporal and nontemporal working memory tasks. Perception \& Psychophysics, 59, 1118-1140.

BROWN, S. W. (1998). Automaticity versus timesharing in timing and tracking dual-task performance. Psychological Research, 61, 71-81.

Brown, S. W., \& BennetT, E. D. (2002). The role of practice and automaticity in temporal and nontemporal dual-task performance. Psychological Research, 66, 80-89.

BROWN, S. W., \& FrIEH, C. T. (2000). Information processing in the central executive: Effects of concurrent temporal production and memory updating tasks. In P. Desain \& L. Windsor (Eds.), Rhythm perception and production (pp. 193-196). Lisse, The Netherlands: Swets \& Zeitlinger.
Brown, S. W., \& Stubbs, D. A. (1992). Attention and interference in prospective and retrospective timing. Perception, 21, 545-557.

BRUGGER, P. (1997). Variables that influence the generation of random sequences: An update. Perceptual \& Motor Skills, 84, 627-661.

Burle, B., \& Casini, L. (2001). Dissociation between activation and attention effects in time estimation: Implications for internal clock models. Journal of Experimental Psychology: Human Perception \& Performance, 27, 195-205.

CASAli, J. G., \& WierWille, W. W. (1983). A comparison of rating scale, secondary-task, physiological, and primary-task workload estimation techniques in a simulated flight task emphasizing communications load. Human Factors, 25, 623-641.

Casali, J. G., \& Wierwille, W. W. (1984). On the measurement of pilot perceptual workload: A comparison of assessment techniques addressing sensitivity and intrusion issues. Ergonomics, 27, 1033-1050.

CAsini, L., \& IVRY, R. B. (1999). Effects of divided attention on temporal processing in patients with lesions of the cerebellum or frontal lobe. Neuropsychology, 13, 10-21.

CASINI, L., \& MACAR, F. (1997). Effects of attention manipulation on judgments of duration and of intensity in the visual modality. Memory \& Cognition, 25, 812-818.

CASINI, L., Macar, F., \& Grondin, S. (1992). Time estimation and attentional sharing. In F. Macar, V. Pouthas, \& W. J. Friedman (Eds.), Time, action, and cognition: Towards bridging the gap (pp. 177-180). Dordrecht: Kluwer.

Coull, J. T., Vidal, F., Nazarian, B., \& Macar, F. (2004). Functional anatomy of the attentional modulation of time estimation. Science, 303, 1506-1508.

De Rammelaere, S., Stuyven, E., \& Vandierendonck, A. (1999). The contribution of working memory resources in the verification of simple mental arithmetic sums. Psychological Research, 62, 72-77.

Evans, F. J. (1978). Monitoring attention deployment by random number generation: An index to measure subjective randomness. Bulletin of the Psychonomic Society, 12, 35-38.

Evans, F. J., \& Graham, C. (1980). Subjective random number generation and attention deployment during acquisition and overlearning of a motor skill. Bulletin of the Psychonomic Society, 15, 391-394.

Fraisse, P. (1978). Time and rhythm perception. In E. C. Carterette \& M. P. Friedman (Eds.), Handbook of perception: Vol. 8. Perceptual coding (pp. 203-254). New York: Academic Press.

Franssen, V., \& Vandierendonck, A. (2002). Time estimation: Does the reference memory mediate the effect of knowledge of results? Acta Psychologica, 109, 239-267.

FürST, A. J., \& HiTCH, G. J. (2000). Separate roles for executive and phonological components of working memory in mental arithmetic. Memory \& Cognition, 28, 774-782.

GiLhOOLY, K. J., LOGIE, R. H., Wetherick, N. E., \& WynN, V. (1993). Working memory and strategies in syllogistic-reasoning tasks. Memory \& Cognition, 21, 115-124.

GiNSBURG, N., \& KARPIUK, P. (1994). Random generation: Analysis of the responses. Perceptual \& Motor Skills, 79, 1059-1067.

Grondin, S., \& MaCAR, F. (1992). Dividing attention between temporal and nontemporal tasks: A performance operating characteristicPOC - analysis. In F. Macar, V. Pouthas, \& W. J. Friedman (Eds.), Time, action, and cognition: Towards bridging the gap (pp. 119-128). Dordrecht: Kluwer.

Heathcote, D. (1994). The role of visuo-spatial working memory in the mental addition of multi-digit addends. Current Psychology of Cognition, 13, 207-245.

Hicks, R. E., \& Allen, D. A. (1979). The repetition effect in judgments of temporal duration across minutes, days, and months. American Journal of Psychology, 92, 323-333.

Hicks, R. E., Miller, G. W., Gaes, G., \& Bierman, K. (1977). Concurrent processing demands and the experience of time-in-passing. American Journal of Psychology, 90, 431-446.

Hicks, R. E., Miller, G. W., \& Kinsbourne, M. (1976). Prospective and retrospective judgments of time as a function of amount of information processed. American Journal of Psychology, 89, 719-730.

Hirst, W., \& KalmaR, D. (1987). Characterizing attentional resources. Journal of Experimental Psychology: General, 116, 68-81.

Hiscock, M., Cheesman, J., InCh, R., Chipuer, H. M., \& Graff, L. A. 
(1989). Rate and variability of finger tapping as measures of lateralized concurrent task effects. Brain \& Cognition, 10, 87-104.

Kantowitz, B. H., \& KNIGHT, J. L. (1974). Testing tapping timesharing. Journal of Experimental Psychology, 103, 331-336.

Kantowitz, B. H., \& KNIGHT, J. L. (1976). Testing tapping timesharing: II. Auditory secondary task. Acta Psychologica, 40, 343-362.

Kee, D. W., Morris, K., Bathurst, K., \& Hellige, J. B. (1986). Lateralized interference in finger tapping: Comparisons of rate and variability measures under speed and consistency tapping instructions. Brain \& Cognition, 5, 268-279.

KLAPP, S. T., Porter-Graham, K. A., \& HoifJeld, A. R. (1991). The relation of perception and motor action: Ideomotor compatibility and interference in divided attention. Journal of Motor Behavior, 23, 155162.

LEMAIRE, P., ABDI, H., \& FAYOL, M. (1996). The role of working memory resources in simple cognitive arithmetic. European Journal of Cognitive Psychology, 8, 73-103.

LoGIE, R. H., ZUCCO, G. M., \& BADDELEY, A. D. (1990). Interference with visual short-term memory. Acta Psychologica, 75, 55-74.

Macar, F., Grondin, S., \& Casini, L. (1994). Controlled attention sharing influences time estimation. Memory \& Cognition, 22, 673-686.

NAvon, D., \& Gopher, D. (1979). On the economy of the humanprocessing system. Psychological Review, 86, 214-255.

NAvon, D., \& Gopher, D. (1980). Task difficulty, resources, and dualtask performance. In R. S. Nickerson (Ed.), Attention and performance VIII (pp. 297-315). Hillsdale, NJ: Erlbaum.

NeIL, D., \& Towse, J. (1997). RGCalc: Quantifying order in response sequences [Computer software]. Retrieved from www.pc.rhbnc.ac.uk /cdrg/rgepage.html.

NICKERSON, R. S. (2002). The production and perception of randomness. Psychological Review, 109, 330-357.

NoËL, M.-P., DéSERT, M., Aubrun, A., \& SERon, X. (2001). Involvement of short-term memory in complex mental calculation. Memory \& Cognition, 29, 34-42.

O'DONNELl, R. D., \& EGgemeier, F. T. (1986). Workload assessment methodology. In K. R. Boff, L. Kaufman, \& J. P. Thomas (Eds.), Handbook of perception and human performance: Vol. II. Cognitive processes and performance (pp. 42.1-42.49). New York: Wiley.

ORnstein, R. (1969). On the experience of time. New York: Penguin.

Robbins, T. W., Anderson, E. J., Barker, D. R., Bradley, A. C., Fearnyhough, C., Henson, R., ET AL. (1996). Working memory in chess. Memory \& Cognition, 24, 83-93.

Ross, D. A. (1969). Lengthening of time estimates in four different temporal patterns of visual light stimulation. Psychonomic Science, 16, 194-195.

Seitz, K., \& Schumann-Hengsteler, R. (2000). Mental multiplication and working memory. European Journal of Cognitive Psychology, 12, 552-570.

SHANNON, C. E., \& WeAver, W. (1949). The mathematical theory of communication. Urbana: University of Illinois Press.

Shinohara, K. (1999). Resource for temporal information processing in interval production. Perceptual \& Motor Skills, 88, 917-928.

Stuss, D. T., \& Alexander, M. P. (2000). Executive functions and the frontal lobes: A conceptual view. Psychological Research, 63, 289298.

StuYven, E., \& VAN DER Goten, K. (1995). Stimulus independent thoughts and working memory: The role of the central executive. Psychologica Belgica, 35, 241-251.

Teasdale, J. D., Dritschel, B. H., Taylor, M. J., Proctor, L., Lloyd, C. A., Nimmo-Smith, I., \& Baddeley, A. D. (1995). Stimulusindependent thought depends on central executive resources. Memory \& Cognition, 23, 551-559.

THOMAS, E. A. C., \& CANTOR, N. E. (1975). On the duality of simultaneous time and size perception. Perception \& Psychophysics, 18, 44-48.

Thomas, E. A. C., \& Cantor, N. E. (1978). Interdependence between the processing of temporal and non-temporal information. In J. Re- quin (Ed.), Attention and performance VII (pp. 43-62). Hillsdale, NJ: Erlbaum.

Thomas, E. A. C., \& Weaver, W. B. (1975). Cognitive processing and time perception. Perception \& Psychophysics, 17, 363-367.

Towse, J. N., \& NeIL, D. (1998). Analyzing human random generation behavior: A review of methods used and a computer program for describing performance. Behavior Research Methods, Instruments, \& Computers, 30, 583-591.

TowsE, J. N., \& VALENTINE, J. D. (1997). Random generation of numbers: A search for underlying processes. European Journal of Cognitive Psychology, 9, 381-400.

TREISMAN, M. (1963). Temporal discrimination and the indifference interval: Implications for a model of the "internal clock." Psychological Monographs: General \& Applied, 77(13, Whole No. 576).

Tsang, P. S., Shaner, T. L., \& Vidulich, M. A. (1995). Resource scarcity and outcome conflict in time-sharing performance. Perception \& Psychophysics, 57, 365-378

VANDIERENDONCK, A., De Vooght, G., \& VAN DER Goten, K. (1998) Does random time interval generation interfere with working memory executive functions? European Journal of Cognitive Psychology, 10, 413-442.

WiCKENS, C. D. (1980). The structure of attentional resources. In R. S. Nickerson (Ed.), Attention and performance VIII (pp. 239-257). Hillsdale, NJ: Erlbaum.

Wickens, C. D. (1984). Processing resources in attention. In R. Parasuraman \& D. R. Davies (Eds.), Varieties of attention (pp. 63-102). New York: Academic Press.

WiCKENS, C. D. (1986). Gain and energetics in information processing. In G. R. J. Hockey, A. W. K. Gaillard, \& M. G. H. Coles (Eds.), Energetics and human information processing (pp. 373-389). Dordrecht: Martinus Nijhoff.

Wickens, C. D. (1991). Processing resources and attention. In D. L. Damos (Ed.), Multiple-task performance (pp. 3-34). London: Taylor \& Francis.

WiCKENS, C. D. (1992). Engineering psychology and human performance (2nd ed.). New York: HarperCollins.

Wierwille, W. W., \& ConNor, S. A. (1983). Evaluation of 20 workload measures using a psychomotor task in a moving-base aircraft simulator. Human Factors, 25, 1-16.

WierWILle, W. W., RAHIMI, M., \& CASALI, J. G. (1985). Evaluation of 16 measures of mental workload using a simulated flight task emphasizing mediational activity. Human Factors, 27, 489-502.

ZAKAY, D. (1989). Subjective time and resource allocation: An integrated model of time perception. In I. Levin \& D. Zakay (Eds.), Time and human cognition: A life-span perspective (pp. 365-397). Amsterdam: Elsevier.

ZAKAY, D. (1993). Time estimation methods: Do they influence prospective duration estimates? Perception, 22, 91-101.

ZAKAY, D. (1998). Attention allocation policy influences prospective timing. Psychonomic Bulletin \& Review, 5, 114-118.

ZAKAY, D., \& SHUB, J. (1998). Concurrent duration production as a workload measure. Ergonomics, 41, 1115-1128.

\section{NOTE}

1. Temporal productions tended to increase in magnitude across trials. The mean IRI scores for Trials 1, 2, 3, and 4 were 5.2, 5.5, 5.7, and $5.6 \mathrm{sec}$, respectively. A trend analysis confirmed that the increase was linear $\left[F(1,34)=8.53, M S_{\mathrm{e}}=1.10, p<.006\right]$, accounting for $80.6 \%$ of the variance. This pattern of temporal productions becoming progressively longer is an example of the lengthening effect, a classic psychophysical result involving serial productions (Hicks \& Allen, 1979; Ross, 1969; Treisman, 1963).

(Manuscript received October 30, 2003; revision accepted for publication June 29, 2005.) 